\title{
Evaluation of azlocillin in vitro and in discriminative animal models of infection
}

\author{
W. Michael Scheld, James P. Brodenr, John M. Keeley, Mary R. Field, \\ Walter J. Kelly, IV, William J. Long, Jr. and Otokar Zak* \\ Departments of Internal Medicine (Infectious Diseases) and Neurosurgery, \\ University of Virginia School of Medicine, Charlottesville, Virginia 22908, \\ U.S.A. and the Infectious Diseases Research Laboratories, Ciba-Geigy, \\ Basle CH4002, Switzerland*
}

Azlocillin was more active in vitro than ticarcillin or carbenicillin against 561 aminoglycoside-resistant strains of Pseudomonas aeruginosa collected from 74 hospitals distributed over a wide geographic area in the eastern United States.

Azlocillin was compared with various other antimicrobial agents in discriminative animal models of Ps. aeruginosa pyelonephritis, osteomyelitis, endocarditis, and meningitis in a variety of mammalian species.

Cefsulodin was more effective than azlocillin in reducing Ps. aeruginosa kidney concentrations in rat pyelonephritis induced by intrarenal inoculation. The mean \pm S.D. $\log _{10} \mathrm{cfu} / \mathrm{g}$ kidney after three days of therapy were as follows: controls $=5.4 \pm 1.5$, azlocillin $=4.4 \pm 1.8$, cefsulodin $=2.6 \pm 0.9(P \cdot 0.01)$ but the $\mathrm{MBC}$ for the test strain was eight-fold higher for azlocillin $(8 \mathrm{vs} .1 \mathrm{mg} / \mathrm{l})$ and effective concentrations were maintained longer in rat serum for cefsulodin as against azlocillin. In addition, ticarcillin reduced kidney bacterial concentrations faster than azlocillin in a mouse pyelonephritis model induced by intravenous $P s$. aeruginosa inoculation with subsequent iron loading.

Azlocillin was less effective than tobramycin in experimental chronic $P$ s. aeruginosa osteomyelitis induced in rabbits by direct injection into the tibia. An azlocillin-tobramycin regimen was not more effective than tobramycin alone. After 28 days of therapy, the percentages of positive bone cultures after death were as follows: no antibiotic (controls) $=92 \%$, azlocillin $=95 \%$, tobramycin $=76 \%$, azlocillin plus tobramycin $=60 \%$.

Both ticarcillin and azlocillin were less active than tobramycin in experimental $P s$. aeruginosa endocarditis induced in rabbits by intravenous inoculation of $10^{8} \mathrm{cfu}$ following $1 \mathrm{~h}$ of catheter induced aortic valve trauma. The best results were noted with an azlocillin-tobramycin regimen. The mean \pm S.D. $\log _{10}$ cfu Ps. aeruginosa/g vegetation after five days of therapy were as follows: no antibiotic controls $=8 \cdot 1 \pm 1 \cdot 1$, tobramycin $=4 \cdot 5 \pm 0 \cdot 8$, ticarcillin $=6.9 \pm 0.8$, azlocillin $=5 \cdot 7 \pm 1 \cdot 5$, ticarcillin plus tobramycin $=4 \cdot 9 \pm 1 \cdot 0$, azlocillin plus tobramycin $=3 \cdot 3 \pm 1 \cdot 6$. Sterile vegetations were rarely attained with any regimen.

The mean percentage penetration into purulent cerebrospinal fluid (CSF) in experimental Ps. aeruginosa meningitis for azlocillin was $13.3 \%$, comparable to many other $\beta$-lactam antibiotics. Azlocillin was the single most active $(P<0-01)$ agent evaluated after $8 \mathrm{~h}$ intravenous infusions in this model. An azlocillin-amikacin regimen was more rapidly bactericidal $(P<0.01)$ than either agent alone in vivo. None of the agents evaluated alone or in combination, however, produced a sterile $\mathrm{CSF}$ after $8 \mathrm{~h}$ of therapy in any animal.

Reprint requests to: W. Michael Scheld, M.D., Division of Infectious Diseases, Box 385, University of Virginia School of Medicine, Charlottesville, Virginia 22908, U.S.A. 


\section{Introduction}

Azlocillin is a new ureidopenicillin with a wide in-vitro spectrum of activity, particularly against the Enterobacteriaceae and Pseudomonas aeruginosa (Calderwood et al., 1982; Coppens \& Klastersky, 1979; Eliopoulos \& Moellering, 1982; Ellis et al., 1979; Fass, 1982; Fu \& Neu, 1978; Greenwood \& Eley, 1982; Hoogkamp-Korstanje, Pot \& Westerdaal, 1981; Neu \& Fu, 1978; Slack, 1981; Tselentis et al., 1981 ; White, Comber \& Sutherland, 1980; White et al., 1979; Wise, Andrews \& Bedford, 1978a). The in-vitro activity against $P$ s. aeruginosa surpasses carbenicillin, ticarcillin, and mezlocillin, and is comparable to piperacillin and cefsulodin (King, Shannon \& Phillips, 1980; Kuck, Testas \& Forbes, 1981; Perea et al., 1980; Wise et al., 1978b). Because of these excellent in-vitro properties, all of these agents have been investigated in experimental animal models of infection. Unlike mezlocillin (Scheld, Brodeur \& Keeley, 1981), azlocillin has been evaluated in a wide variety of discriminative experimental models. Most of the data is either unpublished or available only in abstract form.

Three main types of experimental models are used in experimental chemotherapy: basic screening (i.e. the mouse protection test), ex vivo, or discriminative. The first two types suffer from multiple inherent problems but discriminative models generally simulate known pathogenic mechanisms more closely (Zak, 1980; Scheld \& Sande, 1982). Only discriminative models are considered in this review.

The objective of this study was to describe the cumulative experience with azlocillin in discriminative animal models of infection. This analysis considers published results in experimental osteomyelitis and pyelonephritis (Norden \& Shaffer, 1982; Beale, Comber \& Sutherland, 1982) as well as our own unpublished, but reported, data in experimental pyelonephritis, endocarditis, and meningitis.

\section{Methods}

General analysis. A thorough literature search disclosed that the in-vivo activity of azlocillin was evaluated and reported in only two previous studies of experimental osteomyelitis and pyelonephritis (Norden \& Shaffer, 1982; Beale et al., 1982). These experiments are summarized below. Other studies were identified through Drs George Arcieri and Douglas Webb (Miles Pharmaceuticals, West Haven, Connecticut, U.S.A.) and personal communication with other investigators active in the field of experimental antibacterial chemotherapy. Data were kindly provided by Dr Otokar Zak of Ciba-Geigy Ltd. (Basle, Switzerland) on experimental pyelonephritis; these experiments are also summarized below.

In-vitro studies. Minimal inhibitory concentrations (MICs) and minimal bactericidal concentrations (MBCs) were determined for azlocillin and the other agents studied in the experimental animal models of infection by standard broth microdilution techniques (Cooke Engineering Co., Alexandria, Virginia, U.S.A.). After overnight $(18 \mathrm{~h})$ incubation, the organisms were centrifuged $(3000 \mathrm{~g} \times 15 \mathrm{~min})$, washed twice in physiologic saline, and serially diluted to ensure an inoculum of $5 \times 10^{5} \mathrm{cfu} / \mathrm{ml}$ Mueller-Hinton broth (Difco). The MIC was read as the lowest concentration of antibiotic that inhibited visible turbidity after $18 \mathrm{~h}$ incubation at $37^{\circ}$; the $\mathrm{MBC}$ was taken as the lowest concentration of drug that completely sterilized the wells as verified by subculture onto drug free media and further incubation at $37^{\circ}$ for $24 \mathrm{~h}$. 
In addition to determination of broth dilution MICs and MBCs for the Ps. aeruginosa strains used in the in-vivo experiments, Mueller-Hinton agar dilution MICs (inoculum $=5 \times 10^{5} \mathrm{cfu}$ ) were determined for azlocillin, ticarcillin and carbenicillin against 561 strains of Ps. aeruginosa isolated from multiple sites collected from 74 hospitals spread over a wide geographic area as part of an ongoing surveillance system for antibiotic resistance among aerobic Gram-negative bacillary nosocomial isolates (Wenzel et al., 1979). Concentrations of $2-32 \mathrm{mg} / \mathrm{l}$ of each antibiotic were incorporated into the agar; the strains were deposited on the surface with a Steer's replicator (Steers, Foltz \& Graves, 1959). The results were read after $24 \mathrm{~h}$ of incubation at $37^{\circ}$.

Preparation of bacteria. The Ps. aeruginosa strains used in the in-vivo experiments (see below) were all clinical isolates and the inocula were prepared by similar methods. The organisms were grown for 16 to $18 \mathrm{~h}$ in trypticase soy broth (TSB; Difco) at $37^{\circ}$, centrifuged at $3000 \mathrm{~g} \times 15 \mathrm{~min}$, and washed twice in non-bacteriostatic physiologic saline. The pellet was resuspended in $2.0 \mathrm{ml}$ PBS and serial diluted ten-fold in PBS prior to quantitative determinations in trypticase soy agar pour plates. The inoculum varied with the experimental model of infection under consideration from $\simeq 10^{6}$ to $>10^{8}$ (see below).

Experimental pyelonephritis. Azlocillin was compared with cefsulodin in experimental pyelonephritis induced in male $180-200 \mathrm{~g}$ Wistar rats by the intrarenal inoculation of $10^{6} \mathrm{cfu} P$ s. aeruginosa (ATCC 12055). Both agents were administered at a dosage of $1 \mathrm{mg} / \mathrm{kg}$ subcutaneously twice daily for three days, beginning $6 \mathrm{~h}$ after inoculation. Quantitative renal cultures were performed $36 \mathrm{~h}$ after the last dose by standard homogenization, serial dilution, and pour plate techniques on CLED agar (Oxoid). The results were expressed as cfu/g kidney and the number of sterile kidneys/total number animals treated in each group.

Another model (Beale et al., 1982) compared the ureidopenicillins with ticarcillin in experimental $P$ s. aeruginosa pyelonephritis induced in mice by the intravenous administration of $2 \times 10^{6} \mathrm{cfu}$ followed by the intramuscular injection of $30 \mathrm{mg} / \mathrm{kg}$ of iron 18,42 , and $66 \mathrm{~h}$ after injection. Therapy was instituted at either 19 or 43 hours after infection, at varying dosages, and continued four times daily for three days. Three strains of Ps. aeruginosa were used in these experiments. The results were assessed as the percentage of kidneys with macroscopic abscesses and viable count deteminations of kidney homogenates by standard techniques counted seven days after infection.

Experimental osteomyelitis. Chronic Ps. aeruginosa osteomyelitis was induced in rabbits by the intramedullary injection into the tibia of $2 \times 10^{7} \mathrm{cfu}$ plus sodium morrhuate (Norden \& Shaffer, 1982). The model was developed from methods used previously to induce chronic staphylococcal osteomyelitis (Norden, 1970), and, by radiographic and pathological criteria, closely simulates the human disease (Norden, Myerowitz \& Keleti, 1980). Treatment was begun 14 days after inoculation and continued for 14 or 28 days. The dosages (in $\mathrm{mg} / \mathrm{kg}$, all given subcutaneously) of the antibiotics tested were as follows: tobramycin-10, twice daily; azlocillin-400, four times daily. Each agent was administered alone, and in combination, and compared to untreated controls. The animals were killed 70 days after inoculation and bone cultures obtained by flushing the marrow cavity (Norden, 1970). The results were expressed as the percentage of animals with positive bone cultures in each group.

Experimental endocarditis. Endocarditis was induced in $2-3 \mathrm{~kg}$ New Zealand white rabbits by modifications of methods described previously (Archer \& Fekety, 1976, 
1977; Durack, Beeson \& Petersdorf, 1973; Freedman \& Valone, 1979; Scheld et al., 1981, 1982). A polyethylene catheter (Intramedic, Clay-Adams, New Jersey, U.S.A.; PE-90) was introduced through the right carotid artery and threaded across the aortic valve into the ventricle. The catheter was left in place for $\mathrm{l} \mathrm{h}$; this period of trauma uniformly results in the deposition of fibrin and platelets with the production of nonbacterial thrombotic endocarditis (NBTE) on the damaged aortic valvular endothelium (Sande \& Irvin, 1974; Scheld, Valone \& Sande, 1978). After this interval, $6 \times 10^{8} \mathrm{cfu}$ washed $P$ s. aeruginosa in $1.0 \mathrm{ml}$ saline were injected intravenously. The strain was isolated originally from a fatal case of endocarditis at the University of Virginia hospital in 1976 and was not serum sensitive. Following inoculation, the catheter was removed and the wound closed. Quantitative blood cultures $(1.0 \mathrm{ml})$ were obtained $24 \mathrm{~h}$ later and treatment begun. The dosages $(\mathrm{mg} / \mathrm{kg})$ were as follows: tobramycin-5; azlocillin and ticarcillin-200. All drugs were given intramuscularly every $8 \mathrm{~h}$ for five days. Blood was drawn frequently (i.e. $0 \cdot 5,1,1 \cdot 5,2,3,4,6$, and $8 \mathrm{~h}$ ) for determination of serum antibiotic levels on the second day of therapy. In addition, blood was obtained for determination of 'peak' and 'trough' serum bactericidal activity against the infecting strain. Only febrile animals with positive blood cultures (mean $\left.=\log _{10} 2.6 \mathrm{cfu} / \mathrm{ml}\right)$ were considered infected $(>95 \%$ of those catheterized) and included in the analysis.

The animals were killed $8 \mathrm{~h}$ after the last dose of antibiotic(s). The aortic valve with vegetations was removed aseptically, weighed, homogenized, and titered by serial ten-fold dilutions onto trypticase soy agar pour plates. The results were expressed as the mean $\pm \log _{10}$ Ps. aeruginosa $\mathrm{cfu} / \mathrm{g}$ of vegetation. At least ten rabbits were included in each treatment group.

Experimental meningitis. Meningitis was induced in $2-3 \mathrm{~kg}$ New Zealand white rabbits by modifications of methods described previously (Dacey \& Sande, 1974; Scheld et al., 1979a,b, 1982). A dental acrylic helmet was attached to the animal's skull to facilitate rigid immobilization within a stereotaxic frame. After a two or three day interval, and light pentobarbital $(30 \mathrm{mg} / \mathrm{kg})$ anaesthesia, the rabbits were positioned in the stereotaxic frame. The cisterna magna was entered percutaneously with a 25 gauge $\times 3.5$ in Quincke spinal needle mounted in a geared electrode introducer. After withdrawal of 0.35 clear CSF, the inoculum $\left(10^{7}\right.$ cfu Ps. aeruginosa in $0.15 \mathrm{ml}$ saline) was injected slowly and the animals returned to their cages. All rabbits developed meningitis as manifested by fever $\left(>40^{\circ} \mathrm{C}\right.$ ), neurologic signs (e.g. seizures, opisthotonus, lethargy), a CSF pleocytosis (mean $\log _{10} 3.6 \mathrm{wbc} / \mathrm{mm}^{3} \mathrm{CSF} ; \quad 295 \%$ polymorphonuclear leukocytes), and CSF Pseudomonas concentrations that ranged from $10^{4}$ to $>10^{8} \mathrm{cfu} / \mathrm{ml}$ (mean $\log _{10} 6.02 \mathrm{cfu} / \mathrm{ml} \mathrm{CSF}$ ). The meningitis was uniformly fatal in untreated animals with death occurring $\leq 42 \mathrm{~h}$ after inoculation.

After reinduction of anaesthesia, placement of polyethylene catheters (Intramedic PE-90, Clay-Adams, Parsippany, N.J., U.S.A.) in the femoral artery and vein, and repositioning in the stereotaxic frame with intracisternal needles in place, treatment was begun $18 \mathrm{~h}$ after inoculation. All antibiotics were given via continuous intravenous infusion over $8 \mathrm{~h}$ by a syringe infusion pump (Sage model 352) attached to the femoral venous catheter, at the following dosages (in $\mathrm{mg} / \mathrm{kg} / \mathrm{h}$ ): all $\beta$-lactams -80 ; all aminoglycosides-2.5. A loading dose, representing $20 \%$ of the total dose delivered over the $8 \mathrm{~h}$ interval, was given by short $(2-3 \mathrm{~min})$ intravenous bolus infusion immediately prior to the start of therapy. Serum $(3 \mathrm{ml})$ and CSF $(0.25 \mathrm{ml})$ samples were removed from the femoral arterial catheter and cisterna magna, respectively, 
immediately before and after 4 and $8 \mathrm{~h}$ of treatment for quantitative bacterial and antibiotic concentrations. CSF bacterial titers were quantitated by standard ten-fold serial dilution techniques, as well as direct plating $(0.1 \mathrm{ml})$ on trypticase soy agar pour plates. The remainder of the CSF, along with the serum samples, were frozen at $-70^{\circ}$ until antibiotic assays were performed ( $S 1$ week). This period of storage did not affect the assay results.

Antibiotic assays. Antibiotic levels were determined by agar well diffusion methods. Bacillus subtilis spore suspension $(0.9 \mathrm{ml})$ was added to $1000 \mathrm{ml}$ antibiotic medium no. 1 (Baltimore Biologic Laboratories, U.S.A.) for all penicillin assays, including azlocillin. Aminoglycoside concentrations were assayed with a multidrug resistant strain of Staphylococcus epidermidis (ATCC 27626) as described previously (Alcid \& Seligman, 1973). Cefsulodin concentrations were determined with a $2.5 \% \mathrm{v} / \mathrm{v}$ suspension of Sarcina lutea (ATCC 9341) in antibiotic medium no. 1, previously adjusted to yield $21 \%$ transmission at $580 \mathrm{~nm}$ on a Gilford spectrophotometer. All specimens and standards were tested in triplicate. Serum standards were made fresh on the day of assay with appropriate diluent (e.g. rabbit or rat serum), while CSF standards were prepared in $0.9 \% \mathrm{NaCl}$ after equivalent zone sizes were noted after dilution in $0.9 \% \mathrm{NaCl}$, infected or uninfected rabbit CSF.

Analysis of data. When the end-point for analysis of therapy was cfu/unit tissue (e.g. kidney, vegetation, CSF etc.), Student's $t$-test on unpaired data was used to detect any differences between regimens. When the end-point was percentage sterility (or per cent with positive cultures), $\chi^{2}$ analysis with Yate's correction was used. The per cent penetration of antibiotics into the CSF was defined by the formula: CSF concentration/serum concentration $\times 100$.

\section{Results}

In-vitro studies. The MBCs obtained with each of the Ps. aeruginosa strains used in the in-vivo models of experimental infection are shown below in the appropriate tables. The MICs obtained for azlocillin, ticarcillin, and carbenicillin against 561 isolates of $P$ s. aeruginosa collected from nosocomial infections in $\mathbf{7 4}$ hospitals from a four state geographic area in the eastern United States are displayed in Figure 1. Azlocillin was the most active anti-pseudomonal $\beta$-lactam agent tested. For example, at a concentration of $8 \mathrm{mg} / \mathrm{l}$, the percentage of strains inhibited by each agent was as follows: azlocillin $-65 \cdot 1 \%$, ticarcillin-14.4\%, carbenicillin-3.2\%. The median MICs were as follows (in $\mathrm{mg} / \mathrm{l}$ ): azlocillin-8, ticarcillin-16, and carbenicillin $-\geq 64$. Azlocillin was equally active against carbenicillin-sensitive or resistant (MIC $\geq 128 \mathrm{mg} / \mathrm{l}$ ) Ps. aeruginosa isolates in this study (data not shown).

Experimental pyelonephritis. Azlocillin was less active than cefsulodin in the rat pyelonephritis model when analysed in terms of $\log _{10}$ cfu Ps. aeruginosa/g kidney or the total number of positive kidney cultures obtained (Table I). When given at identical dosages $(1 \mathrm{mg} / \mathrm{kg}$ bid $\times 3$ days) kidney bacterial concentrations were higher $(P$ - 0.01) after azlocillin therapy when compared to cefsulodin. Even when the azlocillin dosage was increased to 5 or $10 \mathrm{mg} / \mathrm{kg}$ per injection, the mean recovery of $P s$. aeruginosa still exceeded 4 logs per kidney (O. Zak, pers. comm.). However, the MBC for the test strain was eight-fold higher for azlocillin than cefsulodin. In addition, as shown in Figure 2, therapeutic concentrations of cefsulodin are maintained in rat 


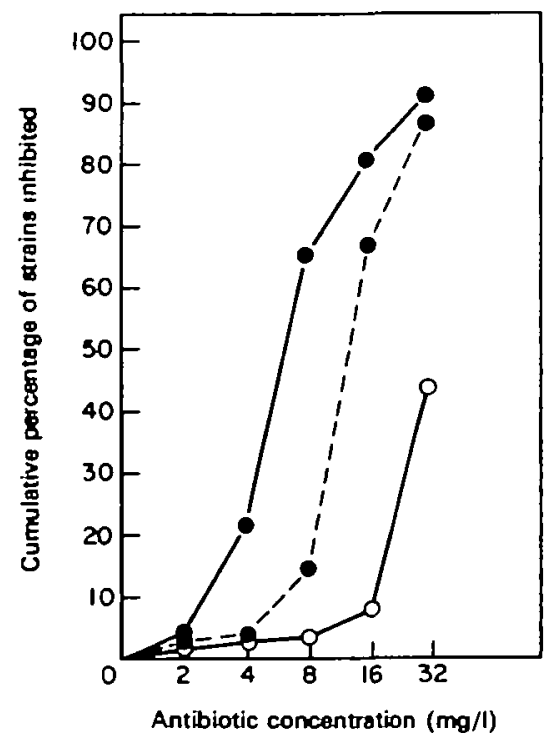

Figure 1. Cumulative percentage of Ps. aeruginosa strains $(n=561)$ inhibited vs. antibiotic concentration $(\mathrm{mg} / \mathrm{l})$ for: azlocillin $(0-0)$, ticarcillin $(-0)$, and carbenicillin $(\mathrm{O}-\mathrm{O})$.

serum for much longer periods than was noted after equivalent (or higher) dosages of azlocillin.

Azlocillin was less effective than ticarcillin in the mouse model of experimental Ps. aeruginosa pyelonephritis as well (Table ID). The results are expressed as the percentage of animals with macroscopically visible abscesses on the cortical surface after death which correlates well with kidney tissue homogenate viable counts of $\geq 10^{7} \mathrm{cfu} / \mathrm{g}$. When the antibiotics were begun $19 \mathrm{~h}$ after infection, azlocillin at $125 \mathrm{mg} / \mathrm{kg}$ did not prevent abscess formation but ticarcillin produced $60 \%$ negative cultures at the same dosage. Similar differences were noted after a higher dosage of $500 \mathrm{mg} / \mathrm{kg}$ against this Ps. aeruginosa strain NCTC 10662 (Table II; Beale et al., 1982). When antibiotic therapy was delayed until $43 \mathrm{~h}$ post-infection, mean kidney bacterial concentrations had increased to $\simeq 10^{5} \mathrm{cfu} / \mathrm{g}$ from the value of $\simeq 10^{2} \mathrm{cfu} / \mathrm{g}$ at $19 \mathrm{~h}$, the efficacy of therapy was attenuated, but ticarcillin still rendered more kidneys free of infection than did azlocillin (Table II). When these experiments were extended to two other strains of Ps. aeruginosa in the same animal model, ticarcillin proved more effective than azlocillin and piperacillin at identical dosages of $250 \mathrm{mg} / \mathrm{kg}$; mezlocillin

Table I. Results of therapy in experimental Ps. aeruginosa pyelonephritis*

\begin{tabular}{lccc}
\hline Drug & MBC (mg/l) & $\begin{array}{c}\text { Mean } \pm \text { S.D. } \\
\log _{10} \text { cfu/g kidney }\end{array}$ & $\begin{array}{c}\text { No. positive kidney cultures/ } \\
\text { total no. treated }\end{array}$ \\
\hline None & - & $5 \cdot 4 \pm 1 \cdot 5$ & $12 / 12$ \\
Azlocillin & 8 & $4 \cdot 4 \pm 1 \cdot 8$ & $8 / 10$ \\
Cefsulodin & 1 & $2 \cdot 6 \pm 0.9$ & $1 / 12$ \\
\hline
\end{tabular}

*After Zak, O, Tosch, W. \& Kradolfer F. (1980). Therapeutic efficacy of cefsulodin in severe experimental $P$ s. aeruginosa infections. 20th Interscience Conference on Antimicrobial Agents and Chemotherapy. Abstract no. 460 ; and Zak, O., personal communication. 


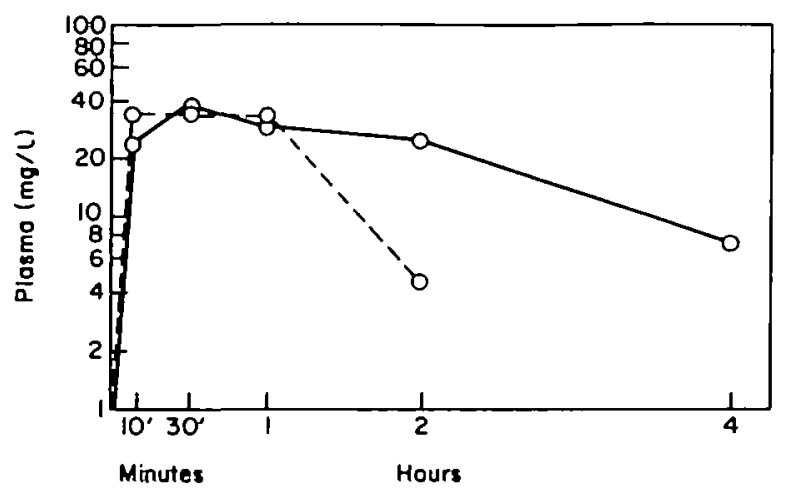

Fhgre 2. Pharmacokinetics of azlocillin $(50 \mathrm{mg} / \mathrm{kg} ; \odot--\odot)$ and cefsulodin $(30 \mathrm{mg} / \mathrm{kg} ; \odot-\odot)$ after subcutaneous injection in adult rats. Mean plasma concentration $(\mathrm{mg} / \mathrm{l})$ vs. time after injection $(\mathrm{h})$.

was the least active agent in this setting (data not shown; Beale et al., 1982).

Experimental osteomyelitis. The results of therapy in the model of chronic Ps. aeruginosa osteomyelitis are shown in Table III. The severity of the disease, as judged by radiographic criteria, was similar in each group and approximately $30 \%$ of the animals had developed sequestra before death, 70 days after inoculation. The data are presented for the 28 day treatment regimens only. Azlocillin alone was no more effective than no treatment ( $>90 \%$ positive bone cultures); tobramycin alone was more effective (Table III). The azlocillin-tobramycin combination regimen was more effective than either no treatment or azlocillin alone $\left(P-0.05\right.$ by $\chi^{2}$ analysis) but was not significantly more effective than tobramycin alone (Table III).

Table II. Results of therapy in experimental Ps. aeruginosa pyelonephritis*

\begin{tabular}{lccc}
\hline & & \% Mice with visible kidney abscesses when \\
therapy was begun at: \\
Drug & Dosage $(\mathrm{mg} / \mathbf{k g})$ & $19 \mathrm{~h}$ & $43 \mathrm{~h}$ \\
\hline None & - & 90 & 90 \\
Azlocillin & 125 & 100 & 80 \\
" & 500 & 40 & 70 \\
Ticarcillin & 125 & 40 & 70 \\
$\quad "$ & 500 & 0 & 20 \\
\hline
\end{tabular}

*After Beale et al., (1982).

Table III. Results of therapy in experimental Ps. aeruginosa osteomyelitis*

\begin{tabular}{lccc}
\hline Drug & MIC (mg/l) & Mean 'peak' [bone] mg/g & $\begin{array}{c}\text { \% with positive bone cultures } \\
\text { after 28 days treatment }\end{array}$ \\
\hline None & - & - & 92 \\
Azlocillin & $12 \cdot 5$ & $29 \cdot 0$ & 95 \\
Tobramycin & $0 \cdot 2$ & $2 \cdot 6$ & 76 \\
Azlocillin plus & & 60 \\
$\quad$ tobramycin & & & \\
\hline
\end{tabular}

- After Norden, C. W. \& Shaffer, M.A. (1982). 


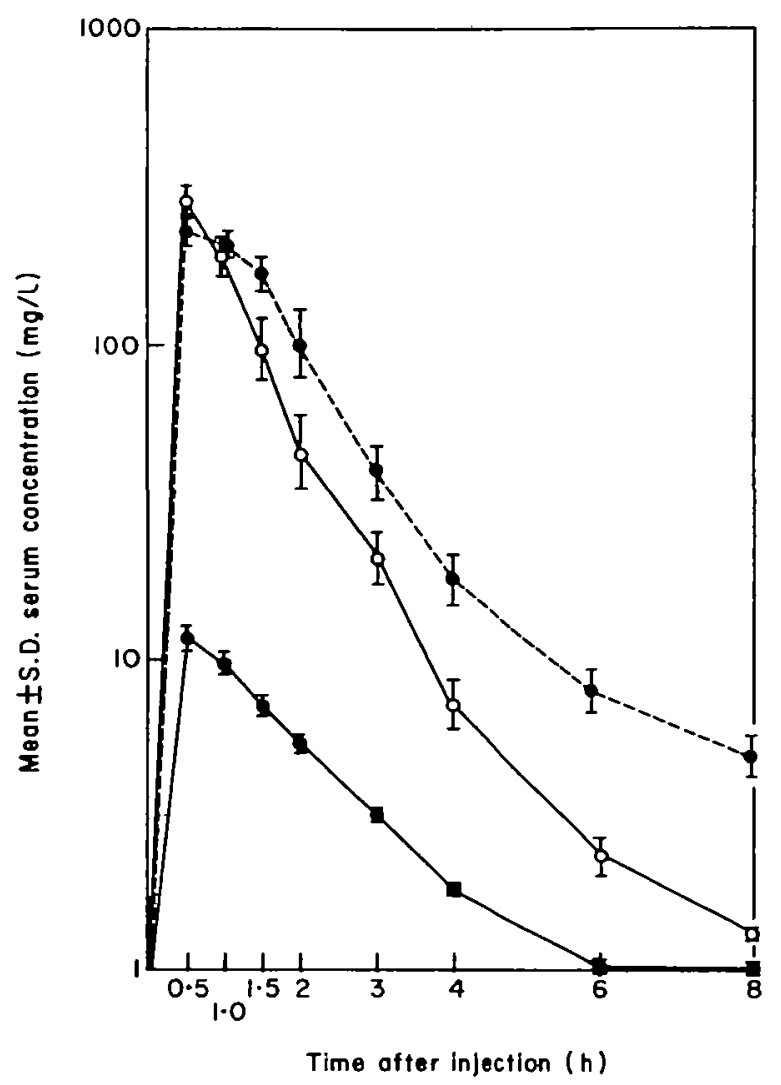

Fkgure 3. Pharmacokinetics of tobramycin $(5 \mathrm{mg} / \mathrm{kg}$; - $)$, azlocillin $(200 \mathrm{mg} / \mathrm{kg}$; --- $)$, and ticarcillin $(200 \mathrm{mg} / \mathrm{kg} ; \mathrm{O}-\mathrm{O})$ after intramuscular injection in adult rabbits with experimental $P s$. aeruginosa endocarditis. Mean \pm S.D. serum concentration $(\mathrm{mg} /)$ vs. time after injection $(\mathrm{h})$.

Experimental endocarditis. The serum concentrations of tobramycin, ticarcillin, and azlocillin in rabbits with experimental endocarditis closely approximated those found in man receiving standard parenteral regimens (Figure 3). The mean 'peak' serum levels occurred $30 \mathrm{~min}$ after im injection and were $11 \cdot 2,285 \cdot 0$, and $228.3 \mathrm{mg} / 1$ for tobramycin, ticarcillin, and azlocillin, respectively. Tobramycin was almost undetectable in serum samples drawn $8 \mathrm{~h}$ after a dose, whereas azlocillin persisted longer in the serum than did ticarcillin after equivalent dosages (Figure 3 ). The median 'peak' serum bactericidal titres were as follows: tobramycin alone-1:2; ticarcillin alone-1:16; azlocillin alone-1:16; azlocillin plus tobramycin-1:32. All trough serum bactericidal titres were $<1: 2$ except for the azlocillin-tobramycin combination regimen where the median (and highest) values were $1: 4$.

The results of therapy of experimental endocarditis in this model are shown in Table IV. The mean bacterial concentration in untreated control vegetations was $\log _{10}$ $8.1 \mathrm{cfu} / \mathrm{g}$, in good agreement with other models of experimental Ps. aeruginosa endocarditis (Archer \& Fekety, 1976, 1977). Tobramycin alone was more effective than either $\beta$-lactam agent alone in reducing Ps. aeruginosa vegetation concentrations after five days of therapy (mean $\log _{10} \mathrm{cfu} / \mathrm{g} 4.5$ vs. $6.9, P-0.01 ; 4.5$ vs. $5.7, P=\mathrm{NS}$ ). The tobramycin-ticarcillin regimen was not more effective than tobramycin alone. 
Table IV. Results of therapy in experimental Ps. aeruginosa endocarditis

\begin{tabular}{lccc}
\hline \multicolumn{1}{c}{ Drug(s) } & MBC (mg/l) & $\begin{array}{c}\text { Mean } \pm \text { s.D. } \\
\text { cfu/g vegetation }\end{array}$ & $\begin{array}{c}\text { No. sterile veg/ } \\
\log _{10}\end{array}$ \\
\hline None & - & $8 \cdot 1 \pm 1 \cdot 1$ & $0 / 10$ \\
Tobramycin & 4 & $4 \cdot 5 \pm 0 \cdot 8$ & $1 / 10$ \\
Ticarcillin & 32 & $6 \cdot 9 \pm 0 \cdot 8$ & $0 / 13$ \\
Azlocillin & 16 & $5 \cdot 7 \pm 1 \cdot 5$ & $1 / 12$ \\
$\begin{array}{l}\text { Tobramycin } \\
\text { ticarcillin }\end{array}$ & & $4 \cdot 9 \pm 1 \cdot 0$ & $2 / 14$ \\
Tobramycin + & & $3 \cdot 3 \pm 1 \cdot 6$ & $4 / 14$ \\
$\quad$ azlocillin & & & \\
\hline
\end{tabular}

Azlocillin plus tobramycin produced the best results with a mean recovery of 3.3 logs at death $(P<0.05$ vs. tobramycin alone; $P<0.01$ vs. azlocillin alone). Sterile vegetations were achieved rarely, however. For example, only 4 of 14 rabbits in the azlocillin-tobramycin combination group had sterile vegetations after five days of therapy vs. 1 of 10 in the tobramycin group ( $P=\mathrm{NS}$ ).

Experimental meningitis. The mean \pm S.D. serum and CSF concentrations obtained and the percentage penetration into infected CSF for the various antibiotics employed in these experiments are shown in Table V. For each antibiotic, serum concentrations reached a 'steady-state' level within $1 \mathrm{~h}$ of intravenous infusion initiation, and closely approximated those found in man receiving standard parenteral regimens. The CSF concentrations reflect these differences in serum concentrations as well as the ability of the agent to cross inflamed meninges and maintain steady-state concentrations within purulent CSF. The mean percentage penetration into the infected CSF was reproducible and consistent for each agent but varied over a wide range. This value was $\geq 25 \%$ for all aminoglycosides, and was similar for structurally-related compounds (e.g. azlocillin and mezlocillin). These values are in close agreement with those reported in other models of experimental meningitis in rabbits (Strausbaugh, Mandaleris \& Sande, 1977; Strausbaugh \& Sande, 1978; Scheld et al., 1979a,b).

The mean CSF concentration exceeded the MBC for the test strain for the aminoglycosides, azlocillin, piperacillin, and cefsulodin. Despite this relationship, the

Table V. Mean serum and cerebrospinal fluid (CSF) concentrations and percentage penetration into the CSF for various antibiotics in experimental $P s$. aeruginosa meningitis

\begin{tabular}{|c|c|c|c|c|}
\hline Drug & No. animals & $\begin{array}{c}\text { Mean } \pm \text { S.D. } \\
\text { (Serum) }\end{array}$ & $\begin{array}{l}\text { Mean } \pm \text { S.D. } \\
\text { (CSF) }\end{array}$ & $\begin{array}{c}\text { Mean \% } \\
\text { penetration }\end{array}$ \\
\hline Gentamicin & 21 & $13 \cdot 1 \pm 3 \cdot 6$ & $4.0 \pm 1.5$ & $28 \cdot 7$ \\
\hline Tobramycin & 19 & $15 \cdot 6 \pm 4 \cdot 1$ & $3.6 \pm 1.5$ & $24 \cdot 4$ \\
\hline Amikacin & 26 & $23 \cdot 2 \pm 5 \cdot 3$ & $8.6 \pm 1.8$ & $35 \cdot 3$ \\
\hline Carbenicillin & 10 & $73 \cdot 2 \pm 31 \cdot 2$ & $6.9 \pm 3.0$ & $9 \cdot 4$ \\
\hline Ticarcillin & 17 & $82.9 \pm 38.8$ & $7 \cdot 8 \pm 3 \cdot 1$ & $9 \cdot 5$ \\
\hline Mezlocillin & 27 & $179.9 \pm 18.9$ & $23 \cdot 7 \pm 5 \cdot 5$ & $13 \cdot 5$ \\
\hline Azlocillin & 31 & $248 \cdot 2 \pm 22 \cdot 4$ & $29 \cdot 4 \pm 11.7$ & $13 \cdot 3$ \\
\hline Piperacillin & 18 & $148.6 \pm 18.4$ & $23 \cdot 3 \pm 4 \cdot 2$ & $15 \cdot 7$ \\
\hline Cefsulodin & 16 & $209.4 \pm 15.6$ & $29.9 \pm 12.8$ & $15 \cdot 0$ \\
\hline
\end{tabular}

$*(\mathrm{CSF}) /($ Serum $) \times 100$. 


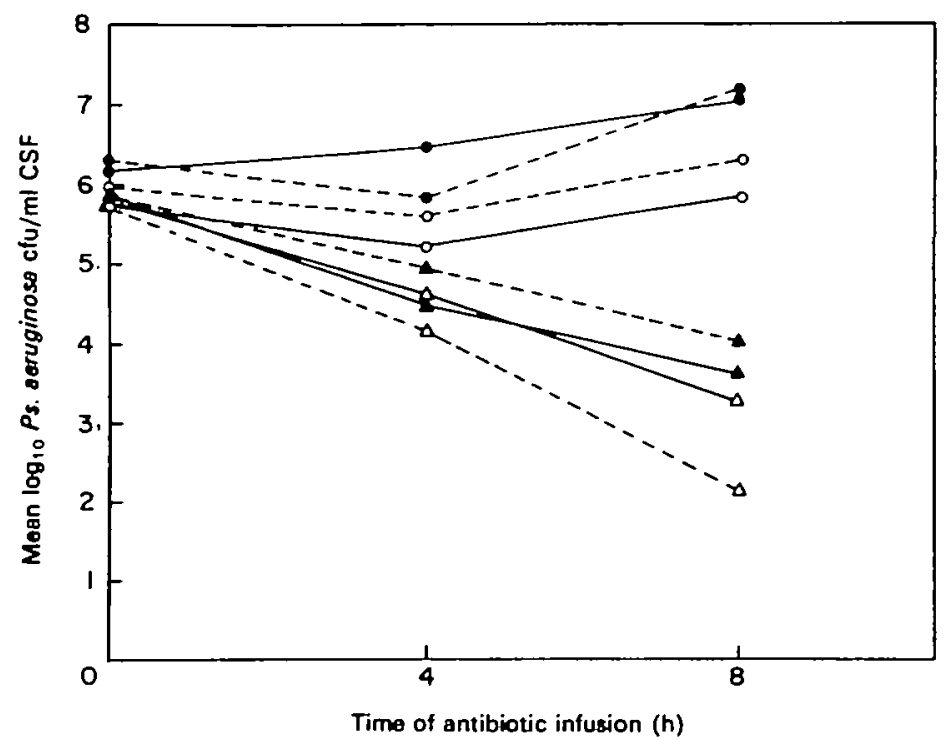

Figure 4. Rate of bacterial killing in experimental Ps. aeruginosa meningitis by: no antibiotic

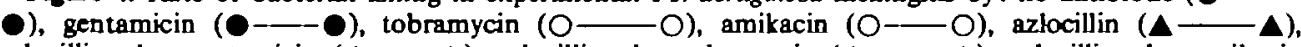
azlocillin plus gentamicin $(\boldsymbol{\Delta}--\Delta)$, azlocillin plus tobramycin $(\triangle-\triangle)$, azlocillin plus amikacin $(\Delta-\triangle)$. Dosages employed (in $\mathrm{mg} / \mathrm{kg} / \mathrm{h}):$ all aminoglycosides $=2.5 ;$ azlocillin $=80$.

rate of bactericidal activity in vivo was poor in this model of experimental $P$ s. aeruginosa meningitis (Table VI; Figure 4). Despite the mean CSF drug concentrations of up to four times the $\mathrm{MBC}$ of the infecting strain, none of the aminoglycosides reduced CSF $P$ s. aeruginosa concentrations when compared to untreated controls (Table VI). Azlocillin was more effective, with a mean reduction of $2 \cdot 1$ logs after $8 \mathrm{~h}$ of therapy $(P<0.01$ vs. aminoglycosides or controls). Azlocillin was the most active $\beta$ lactam agent tested, only ticarcillin and cefsulodin produced declines $>1 \log$ in CSF $P$ s. aeruginosa concentrations after $8 \mathrm{~h}$. Some azlocillin-aminoglycoside regimens were more rapidly bactericidal in vivo than azlocillin alone, but these differences were statistically significant for the azlocillin-amikacin regimen only $(P-0.02$ vs. azlocillin

Table VI. Results of therapy in experimental Ps. aeruginosa meningitis

\begin{tabular}{|c|c|c|c|}
\hline Drug(s) & MBC (mg/l) & Mean $[\mathrm{CSF}] \mathrm{mg} / \mathrm{l}$ & $\begin{array}{c}\text { Mean } \pm \text { S.D. } \triangle \log _{10} \mathrm{cfu} / \mathrm{ml} \mathrm{CSF} \\
\text { after } 8 \mathrm{~h} \text { of therapy }\end{array}$ \\
\hline Gentamicin & 1 & $4 \cdot 0$ & $+0.6 \pm 0.8$ \\
\hline Tobramycin & $i$ & 3.6 & $+0.1 \pm 0.8$ \\
\hline Amikacin & 2 & $8 \cdot 6$ & $+0.3 \pm 0.7$ \\
\hline Azlocillin & 8 & $29 \cdot 4$ & $-2 \cdot 1 \pm 1 \cdot 2$ \\
\hline $\begin{array}{l}\text { Azlocillin }+ \\
\text { gentamicin }\end{array}$ & & & $-1 \cdot 8 \pm 1 \cdot 1$ \\
\hline $\begin{array}{l}\text { Azlocillin }+ \\
\text { tobramycin }\end{array}$ & & & $-2 \cdot 4 \pm 1 \cdot 4$ \\
\hline $\begin{array}{l}\text { Azlocillin }+ \\
\text { amikacin }\end{array}$ & & & $-3.6 \pm 0.8$ \\
\hline None (controls) & & & $+0.8 \pm 0.4$ \\
\hline
\end{tabular}


alone) (Table VI, Figure 4). It should be noted, however, that treatment with a cefsulodin-amikacin regimen produced equivalent results; a mean reduction in CSF bacterial titre of $-3.5 \operatorname{logs}$ in $8 \mathrm{~h}(n=6$; data not shown). None of the regimens examined produced a sterile CSF after the treatment interval in a single animal.

\section{Discussion}

This report summarizes the experience with azlocillin in discriminative animal models of infection. Despite extensive clinical trials conducted in Europe and the United States, information regarding the in-vivo efficacy of azlocillin in experimental infections is scant. This compound has now been evaluated in a wide range of experimental infections recently (all induced by $P$ s. aeruginosa), including pyelonephritis, osteomyelitis, endocarditis and meningitis, and these models are considered in this study. Since azlocillin will be used for serious infections caused by Ps. aeruginosa, including those occurring in neutropenic or other types of immuno-suppressed patients, it is surprising that none of the newer $\beta$-lactam agents has been evaluated in any of the excellent models for bacteraemia in neutropenic animals (Winston et al., 1979; Scheld \& Sande, 1982). Studies with azlocillin and other new $\beta$-lactam agents are currently under investigation in neutropenic animals with a wide variety of experimental infections (Douglas Webb, pers. comm.).

Azlocillin was more active than ticarcillin or carbenicillin against the Ps. aeruginosa isolates tested in vitro in this study (Figure 1). This activity confirms previous reports (Coppens \& Klastersky, 1979; Fu \& Neu, 1979) and is particularly noteworthy since a large number $(n=561)$ of strains from 74 hospitals spread over a wide geographic area were included in the study. Previous evaluations have tested only small numbers of strains from a single institution (e.g. Wise et al., 1978a,b). In addition, the degree of aminoglycoside-resistance was high in the strains tested in the present study. For example, the gentamicin MIC's were $\geq 4$ and $\geq 8 \mathrm{mg} / 1$ for $63 \%$ and $27 \%$ of isolates, respectively; the corresponding figures for tobramycin resistance were $21 \%$ and $15 \%$. Amikacin MIC's were $\geq 8 \mathrm{mg} / 1$ for $42 \%$ of isolates; the MICs were $\geq 16 \mathrm{mg} / 1$ for $19 \%$. Resistance to all three currently available aminoglycosides occurred in $13 \%$ of the Ps. aeruginosa isolates overall. Our present experiments evaluated MIC values only against this large number of isolates; MBCs were done only on the isolates selected for in-vivo study. Some authors have argued that azlocillin (and other ureidopenicillins) are less rapidly bactericidal than ticarcillin (White et al., 1980) while this has not been noted by others (Coppens \& Klastersky, 1979). The clinical relevance requires further experimentation and study, but this type of difference in bactericidal activity may influence the results in vivo in experimental animal models of infection (see below).

Azlocillin was less effective than cefsulodin in the experiments with Ps. aeruginosa pyelonephritis in rats reported here (Table I). Several explanations are possible for this finding. The MBC for the test strain was eight-fold higher for azlocillin than for cefsulodin. In addition, the half-life of azlocillin in rat serum is extremely short, approximately eight minutes (Figure 2; Scheld $e t$ al., unpubl. data) and therapeutic serum levels were maintained with cefsulodin for much longer periods. Indeed, the rat may prove unsuitable for the evaluation of ureidopenicillins in vivo.

Ticarcillin proved more effective in rendering kidneys free of infection than azlocillin in the mouse model of experimental pyelonephritis (Table II; Beale et al., 1982). This may relate to the enhanced bactericidal activity of ticarcillin noted by some 
investigators (White et al., 1980) but the reasons for the differences noted in vivo are not known. The mouse pyelonephritis study does not include data on relative MICs/MBCs, serum or tissue concentrations of antibiotics, the presence of renal failure etc., which may be of critical importance to in-vivo efficacy. All of the drugs evaluated were present in large concentrations in the urine of the experimental mice $(\simeq 350-1100 \mathrm{mg} / \mathrm{l})$ and far exceeded the MIC of the Ps. aeruginosa strains evaluated.

Other factors, including renal concentration of drug, protein-binding in vivo. leukocyte responses, or the generation of a 'post-antibiotic effect' were not pursued and may explain partially differences in in-vivo efficacy in these two models of experimental pyelonephritis. Despite excellent activity against Streptococcus faecalis in vitro, azlocillin has not been evaluated in the well characterized model of rat enterococcal pyelonephritis (Guze, Hubert \& Kalmanson, 1963). Further animal model experiments and clinical trials are necessary to determine if azlocillin (or other new $\beta$-lactams) will be as active as the aminoglycosides (with reduced toxicity) in pyelonephritis due to other pathogens (e.g. ampicillin or carbenicillin resistant Enterobacteriaceae).

Azlocillin was disappointing in the experiments with chronic Ps. aeruginosa osteomyelitis reported here (Table III). When administered alone for 28 days, azlocillin did not reduce the incidence of positive bone cultures after death on day 70 when compared to untreated controls. Similar results were noted with carbenicillin, however (Norden \& Keleti, 1980). The results were improved to a $60 \%$ positive bone culture rate with combined azlocillin-tobramycin therapy, but this was not significantly better than results obtained with tobramycin alone (Table III). In addition, this result is inferior to a $30 \%$ positive bone culture rate obtained with a carbenicillin-sisomicin regimen in an earlier study (Norden \& Keleti, 1980). The reasons for this discrepancy are not entirely clear. The MIC for carbenicillin against the $P$ s. aeruginosa strain used was $62.5 \mathrm{mg} / 1$, vs. $12.5 \mathrm{mg} / \mathrm{l}$ for azlocillin, when an inoculum of $\simeq 10^{5} \mathrm{cfu}$ was used in the in-vitro conditions. A significant 'inoculum effect' was noted for azlocillin against this test isolate when the inoculum was raised to $10^{7} \mathrm{cfu}$ in vitro; the MIC increased from 12.5 to $>500 \mathrm{mg} / \mathrm{l}$ whereas the change with carbenicillin was more modest $(62.5$ to $250 \mathrm{mg} / \mathrm{l}$ ) (Norden \& Shaffer, 1982). This is unlikely to explain the relative efficacy of each drug because of the following factors: (1) bone concentrations rarely exceed $10^{6} \mathrm{cfu}$ in vivo in this model, concentrations where an inoculum effect is not demonstrable in vitro; and (2) the concentrations relevant to the MIC determination at an inoculum of $10^{7} \mathrm{cfu}(\mathrm{e} . \mathrm{g} . \geq 250 \mathrm{mg} / \mathrm{l})$ are far above attainable bone concentrations for either agent. Another possible explanation is the dosing interval used in these experiments. The protocol used permits long intervals between drug dosages (e.g. $\simeq 12 \mathrm{~h}$ ), even with combination regimens, and prolonged periods with suboptimal serum levels resulted. However, identical intervals were used for both the azlocillin-tobramycin and carbenicillin-sisomicin regimens. Finally, no attempt was made for data analysis in regard to differences in the mean $\log _{10}$ cfu Ps. aeruginosa per bone flush obtained after death where 'positive' could indicate as few as $1-2 \mathrm{cfu} / \mathrm{ml}$ of flush. The various treatment regimens may differ when this parameter is used in analysis.

A large number of antibiotics have been evaluated in the well-characterized model of experimental peritonitis and intraabdominal abscess in rats (Bartlett et al., 1981). The model involves the intraperitoneal insertion of gelatin capsules containing caecal contents from meat-fed rats mixed with prereduced peptone yeast glucose broth and 
barium sulphate, and is characterized by an early peritonitis stage caused by coliforms with $\simeq \mathbf{4 0} \%$ mortality followed by a later intra-abdominal abscess stage with Bacteroides fragilis as the predominant isolate (Weinstein et al., 1974; Onderdonk et al., 1974, 1977). In general, antibiotics with anti-coliform activity reduced early mortality, whereas drugs with activity against Bact. fragilis prevented late abscess formation (Weinstein et al., 1975; Bartlett et al. 1978, 1981).

Although azlocillin has not been evaluated in this rat model of peritonitis-intraabdominal abscess, two closely related agents (mezlocillin, piperacillin) were studied recently (Bartlett, Marien \& Dezfulian, 1982) in a subcutaneous abscess model in mice induced by the inoculation of $0.25 \mathrm{ml}$ containing $25 \%$ autoclaved caecal contents plus $10^{7.2} \mathrm{cfu}$ Bact. fragilis strain ATCC 23745 . When the drugs were begun five days after therapy and continued at $600-800 \mathrm{mg} / \mathrm{kg}$ q8h for four doses, pharmacokinetic analysis revealed mean peak abscess concentrations of $44-113 \mathrm{mg} / \mathrm{l}(19-29 \%$ of mean peak serum levels) for carbenicillin, mezlocillin and piperacillin. These results are comparable to those achieved with other $\beta$-lactam agents, and reflect some modest invivo hydrolysis by Bact. fragilis $\beta$-lactamase (Bartlett $e t$ al., 1982). When treatment was begun $1 \mathrm{~h}$ after challenge and continued every $8 \mathrm{~h}$ for five days, and the number of Bact. fragilis/abscess determined at sacrifice, the mean \pm S.E.M. decreases in $\log _{10}$ cfu bacterial concentrations observed were as follows: mezlocillin $=-0.4 \pm 0.1$; carbenicillin $=-1 \cdot 0 \pm 0.3$; piperacillin $=-2.6 \pm 0.6$. These results must be compared with those obtained with drugs employed commonly in Bact. fragilis infections, where the mean \pm S.E.M. decreases in bacterial concentration $\left(\log _{10} \mathrm{cfu} / \mathrm{abscess}\right)$ were as follows: metronidazole $=-6.7 \pm 0.6, \quad$ clindamycin $=-5.0 \pm 0.6 ; \quad$ cefoxitin $=-3.5 \pm 0.5 ;$ and chloramphenicol $=-1.6 \pm 0.5$. Thus, the ureidopenicillins were not as effective as several older agents in this experimental model of Bact. fragilis abscess.

Ps. aeruginosa endocarditis remains a difficult form of this disease in prosthetic valve recipients and intravenous drug abusers (Slaughter, Morris \& Starr, 1973; Reyes et al., 1973). Antimicrobial therapy, usually an aminoglycoside- $\beta$-lactam combination, is rarely curative in Ps. aeruginosa endocarditis involving the left-side of the heart, and mortality rates often exceed $80 \%$. An excellent model of experimental $P$ s. aeruginosa endocarditis was developed by Archer \& Fekety $(1976,1977)$; a modification of this model was used in the experiments with azlocillin-containing regimens reported here.

Although both ticarcillin and azlocillin reduced vegetation Ps. aeruginosa titres significantly $(\cdot 0.05)$ when compared to untreated controls in this model (Table IV), both agents were less effective than tobramycin alone. These results cannot be correlated directly with the serum bactericidal activity measured in vivo with the regimens. Tobramycin alone (at $5 \mathrm{mg} / \mathrm{kg}$ ) was more effective than gentamicin alone (at 5 or $7.5 \mathrm{mg} / \mathrm{kg}$ ) in the earlier studies (Archer \& Fekety, 1977) despite similar MBCs, serum pharmacokinetics and bactericidal activity, even when gentamicin was given for 6 or 14 days as opposed to only five days of tobramycin in our experiments. The tobramycin-ticarcillin regimen was not more effective than tobramycin alone in the present study (Table IV). In contrast, a gentamicin-carbenicillin regimen (at higher dosages) was more effective than either agent alone in the earlier study (Archer \& Fekety, 1977). These differences, however, were only apparent after a full 14 days of therapy and were most noteworthy in prevention of relapses rather than reduction in Ps. aeruginosa concentrations within vegetations. This data is consistent with our short (5 day) treatment intervals, although the incidence of relapse was not evaluated in our study. Although the azlocillin-tobramycin regimen produced the lowest $P$ s. aeruginosa 
concentrations within the vegetations, only 4 of 14 animals had sterile valves on killing after five days. Similar results were obtained after six days of gentamicin-carbenicillin therapy (Archer \& Fekety, 1977) and only $64 \%(9 / 14)$ were sterile after 14 days of treatment with this regimen. Thus, this model of experimental $P s$. aeruginosa endocarditis, like the human disease, is very recalcitrant to antimicrobial therapy, and improved regimens are still needed.

Meningitis due to Gram-negative aerobic bacilli is increasing in frequency (Mangi, Quintiliani \& Andriole, 1975; Crane \& Lerner, 1978; Cherubin et al., 1981) and mortality rates remain distressingly high despite systemic, intrathecal, or intraventricular aminoglycosides alone or in combination with other antimicrobials (McCracken \& Mize, 1976; McCracken, Mize \& Threlkeld, 1980). Ps. aeruginosa is an unusual aetiologic agent in these cases, accounting for $\simeq 5 \%$ of bacterial meningitis in neonates, and is associated with a high mortality rate (Wise, Mathis \& Jawetz, 1969; Johnston \& Speller, 1977). Although therapy of Gram-negative bacillary meningitis may improve with the use of new agents (e.g. moxalactam, cefotaxime), aminoglycosides are still required when the disease is due to $P s$. aeruginosa due to poor activity of these new drugs against this agent at concentrations attainable in purulent CSF in vivo. An experimental model was developed to study these problems in more detail.

A large number of antimicrobials have been evaluated in experimental Ps. aeruginosa meningitis with short $(8 \mathrm{~h}$ ) intravenous infusions (Table V; Scheld, Kelly \& Sande, 1980; Scheld et al., 1982). The percentage penetration ([CSF]/[serum] $\times 100)$ was very reproducible and consistent for each agent (Table $V$ ); these values were usually $\geq 25 \%$ for the aminoglycosides, in close agreement with earlier studies (Strausbaugh \& Sande, 1978). The percentage penetration of mezlocillin and azlocillin were similar $\simeq 13.5 \%$, and this value compares favourably with other $\beta$-lactam agents tested in experimental meningitis (Dacey \& Sande, 1974; Bodine, Strausbaugh \& Sande, 1976; Scheld et al., 1979a,b, 1982; Scheld \& Sande, 1982; Schaad et al., 1981; Perfect \& Durack, 1981; Hodges \& Norley, 1982).

Despite mean CSF antibiotic concentrations that exceeded the MBC of the test strain by several-fold, none of the single-agent regimens was particularly effective in experimental $P_{s}$. aeruginosa meningitis (Table VI, Figure 4). The best results with monotherapy were noted with azlocillin, piperacillin and cefsulodin where the ratio of the CSF concentration to the MBC of the test strain was the highest. Despite this activity, a sterile CSF was never achieved after the $8 \mathrm{~h}$ infusion period. The most rapid bactericidal activity was achieved in vivo with combination therapy, especially azlocillin-amikacin (Table VI). Similar results were obtained with a cefsulodin-amikacin regimen and this, plus other combinations, require further testing. When compared to other forms of experimental meningitis, the rate of decline of Ps. aeruginosa concentration in CSF in this model is slow, despite adequate drug levels in vivo. The reasons for this are not clear but may relate to the low $\mathrm{pH}$ of purulent CSF (mean $=6.95$ in this model) which inhibits aminoglycoside activity, and the slow rate of Ps. aeruginosa growth in CSF ( $>100 \mathrm{~min}$ vs. $20 \mathrm{~min}$ in broth; unpubl. data) which may inhibit the response to cell-wall active agents in vivo. These areas require further study. Azlocillin has been curative in Ps. aeruginosa meningitis in man (Ellis \& Walter, 1979), but carbenicillin has also been effective in selected cases (Mombelli et al., 1982), when an aminoglycoside was also included. None of the new (or old) $\beta$-lactams should be used alone in Ps. aeruginosa meningitis, and the potential 
role for azlocillin in central nervous system infections requires more study.

Azlocillin is an active, new, anti-pseudomonal penicillin with proven efficacy in selected human cases (Eliopoulos \& Moellering, 1982; Eykyn, 1982; Levy, Baran \& Klastersky, 1982). In general, the experiments reported in vivo in the present paper support and extend previous in-vitro observations. Nevertheless, multiple discrepancies between in-vitro MIC/MBC data and in-vivo therapeutic efficacy in animals still exist, and require further study. These models of experimental Ps. aeruginosa infections, like the relevant human disease counterparts, are very resistant to cure with antibiotics, even when given in combination for prolonged periods. Various azlocillin (or piperacillin, cefsulodin)-aminoglycoside regimens appear most active in vivo and may improve results in humans. It should be noted, however, that animal models may be discriminative or predictive but still suffer from difficulties in interpretation (Brown, 1981); the ultimate significance of the experiments reported in the present study require properly controlled prospective clinical trials.

\section{References}

Alcid, D. V. \& Seligman, S. J. (1973). Simplified assay for gentamicin in the presence of other antibiotics. Antimicrobial Agents and Chemotherapy 3, 559-61.

Archer, G. \& Fekety, F. R. Jr. (1976). Experimental endocarditis due to Pseudomonas aeruginosa I. Description of a model. Journal of Infectious Diseases 134, 1-7.

Archer, G. \& Fekety, F. R. Jr. (1977). Experimental endocarditis due to Pseudomonas aeruginosa II. Therapy with carbenicillin and gentamicin. Journal of Infectious Diseases 136, $327-35$.

Bartlett, J. G., Onderdonk, A. B., Louie, T. J., Kasper, D. L. \& Gorbach, S. L. (1978). Lessons from an animal model of intra-abdominal sepsis. Archives of Surgery 113, 853-7.

Bartlett, J. G., Louie, T. J., Gorbach, S. L. \& Onderdonk, A. B. (1981). Therapeutic efficacy of 29 antimicrobial regimens in experimental intra-abdominal sepsis. Reviews of Infectious Diseases 3, 535-42.

Bartlett, J. G., Marien, G. J. \& Dezfulian, M. (1982). Relative efficacy of piperacillin, mezlocillin, and carbenicillin versus Bacteroides fragilis in a mouse model. Current Chemotherapy and Immunotherapy: Proceedings of the 12th International Congress of Chemotherapy $1,54$.

Beale, A. S., Comber, K. R. \& Sutherland, R. (1982). Relative efficacies of ticarcillin and ureidopenicillins (azlocillin, mezlocillin, piperacillin) against experimental Pseudomonas aeruginosa pyelonephritis in mice. Current Chemotherapy and Immunotherapy: Proceedings of the 12th International Congress of Chemotherapy 1, 668-9.

Bodine, J. A., Strausbaugh, L. J. \& Sande, M. A. (1976). Ampicillin and an ester in experimental Haemophilus influenzae meningitis. Clinical Pharmacology and Therapeutics 3, 727-32.

Brown, D. R. J. (1981). Animal models as predictors of therapeutic efficacy in bacterial infections in humans. Journal of Antimicrobial Chemotherapy 7, 213-5.

Calderwood, S. B., Gardella, A., Philippou, A. M., Jacoby, G. A. \& Moellering, R. C. Jr. (1982). Effects of azlocillin in combination with clavulanic acid, sulbactam, and $N$. formimidoyl thienamycin against $\beta$-lactamase producing, carbenicillin-resistant Pseudomonas aeruginosa. Antimicrobial Agents and Chemotherapy 22, 266-71.

Cherubin, C. E., Marr, J. S., Sierra, M. F. \& Becker, S. (1981). Listeria and Gram-negative bacillary meningitis in New York City, 1972-1979. Frequent causes of meningitis in adults. American Journal of Medicine 77, 199-209.

Coppens, L. \& Klastersky, J. (1979). Comparative study of anti-pseudomonas activity of azlocillin, mezlocillin, and ticarcillin. Antimicrobial Agents and Chemotherapy 15, 396-9.

Crane, L. R. \& Lerner, A. M. (1978). Non-traumatic Gram-negative bacillary meningitis in the Detroit Medical Center, 1964-1974. With special mention of cases due to Escherichia coli. Medicine 57, 197-209.

Dacey, R. G. Jr. \& Sande, M. A. (1974). Effect of probenicid on cerebrospinal fluid 
concentrations of penicillin and cephalosporin derivatives. Antimicrobial Agents and Chemotherapy 6, 437-41.

Durack, D. T., Beeson, P. B. \& Petersdorf, R. G. (1973). Experimental bacterial endocarditis III. Production and progress of the disease in rabbits. British Journal of Experimental Pathology 54, 142-51.

Eliopoulos, G. M. \& Moellering, R. C. Jr. (1982). Azlocillin, mezlocillin, and piperacillin: New broad-spectrum penicillins. Annals of Internal Medicine 97, 755-60.

Ellis, C. J., Geddes, A. M., Davey, P. G., Wise, R., Andrews, J. M. \& Grimley, R. P. (1979). Mezlocillin and azlocillin: An evaluation of two new $\beta$-lactam antibiotics. Journal of Antimicrobial Chemotherapy 5, 517-25.

Ellis, C. J. \& Walter, P. H, (1979). Pseudomonas meningitis treated with azlocillin. British Medical Journal ii, 767.

Eykyn, S. J. (1982). Azlocillin in the treatment of serious infection with Pseudomonas aeruginosa. Journal of Antimicrobial Chemotherapy 9, 395-403.

Fass, R. J. (1982). Comparative in vitro activities of azlocillin-cefotaxime and azlocillin-tobramycin combinations against blood and multidrug-resistant bacterial isolates. Antimicrobial Agents and Chemotherapy 22, 167-9.

Freedman, L. R. \& Valone, J. A. Jr. (1979). Experimental infective endocarditis. Progress in Cardiovascular Diseases 22, 169-80.

Fu, K. P. \& Neu, H. C. (1978). Azlocillin and mezlocillin: new ureidopenicillins. Antimicrobial Agents and Chemotherapy 11, 930-8.

Greenwood, D. \& Eley, A. (1982). A turbidimetric study of the responses of selected strains of Pseudomonas aeruginosa to eight anti-pseudomonal $\beta$-lactam antibiotics. Journal of Infectious Diseases 145, 110-7.

Guze, L. B., Hubert, E. G. \& Kalmanson, G. M. (1963). Pyelonephritis II. Observations on the treatment of enterococcal infection in the non-obstructed kidney of the rat. Journal of Laboratory and Clinical Medicine 62, 90-102.

Hodges, G. R. \& Worley, S. E. (1982). Comparative penetration of azlocillin and mezlocillin into cerebrospinal fiuid of normal rabbits and rabbits with experimentally induced Pseudomonas aeruginosa meningitis. Antimicrobial Agents and Chemotherapy 22, 909-11.

Hoogkamp-Korstanje, J. A. A., Pot, C. M. \& Westerdaal, N. A. C. (1981). In vitro activity of cefoperazone and penicillins alone and in combination with aminoglycosides against Pseudomonas aeruginosa. Journal of Antimicrobial Chemotherapy 8, 101-6.

Johnston, P. G. B. \& Speller, D. C. E. (1977). Successful treatment of Pseudomonas aeruginosa septicaemia and meningitis with neutropenia-the presenting feature of hypogammaglobulinaemia. Postgraduate Medical Journal 53, 334-7.

King, A., Shannon, K. \& Phillips, I. (1980). In vitro antibacterial activity and susceptibility of cefsulodin, an anti-Pseudomonal cephalosporin, to beta-lactamases. Antimicrobial Agents and Chemotherapy 17, 165-9.

Kuck, N. A., Testas, R. T. \& Forbes, M. (1981). In vitro and in vivo antibacterial effects of combinations of Beta-lactam antibiotics. Antimicrobial Agents and Chemotherapy 19, 634-8.

Levy, J., Baran, D. \& Klastersky, J. (1982). Anti-Pseudomonas activity of azlocillin during pulmonary infection in patients with cystic fibrosis. Journal of Antimicrobial Chemotherapy $10,235-8$.

Mangi, R. M., Quintiliani, R. \& Andriole, V. T. (1975). Gram-negative bacillary meningitis. American Journal of Medicine 59, 829-36.

McCracken, G. H. Jr. \& Mize, S. G. (1976). A controlled study of intrathecal antibiotic therapy in Gram-negative enteric meningitis of infancy. Journal of Pediatrics 89, 66-72.

McCracken, G. H. Jr., Mize, S. G. \& Threlkeld, N. (1980). Intraventricular gentamicin therapy in Gram-negative meningitis of infancy. Lancet $i, 787-91$.

Mombelli, G., Coppens, L., Husson, M., Brihaye, J. \& Klastersky, J. (1982). Carbenicillin in treatment of meningoventriculitis due to Pseudomonas aeruginosa. Journal of Antimicrobial Chemotherapy 10, 249-53.

Neu, H. C. \& Fu, K. P. (1978). Synergy of azlocillin and mezlocillin combined with aminoglycoside antibiotics and cephalosporins. Antimicrobial Agents and Chemotherapy 13, 813-9.

Norden, C. (1970). Experimental osteomyelitis I. A description of the model. Journal of Infectious Diseases 122, 410-8. 
Norden, C., Myerowitz, R. \& Keleti, E. (1980). Experimental osteomyelitis due to Staphylococcus aureus or Pseudomonas aeruginosa: a radiographic-pathological correlative analysis. British Journal of Experimental Pathology 61, 451-60.

Norden, C. W. \& Keleti, E. (1980). Experimental osteomyelitis caused by Pseudomonas aeruginosa. Journal of Infectious Diseases 141, 71-5.

Norden, C. W. \& Shaffer, M. A. (1982). Activities of tobramycin and azlocillin alone and in combination against experimental osteomyelitis caused by Pseudomonas aeruginosa. Antimicrobial Agents and Chemotherapy 21, 62-5.

Onderdonk, A. B., Weinstein, W. M., Sullivan, N. M., Bartlett, J. G. \& Gorbach, S. L. (1974). Experimental intra-abdominal abscesses in rats: quantitative bacteriology of infected animals. Infection and Immunity 10, 1256-9.

Onderdonk, A. B., Bartlett, J. G., Louie, T., Sullivan-Seigler, N. \& Gorbach, S. L. (1976). Microbial synergy in experimental intra-abdominal abscess. Infection and Immunity 13, 22-6.

Onderdonk, A. B., Kasper, D. L., Cisneros, R. L. \& Bartlett, J. G. (1977). The capsular polysaccharide of Bacteroides fragilis as a virulence factor: comparison of the pathogenic potential of encapsulated and unencapsulated strains. Journal of Infectious Diseases 136, 82-9.

Perea, E. J., Nogales, M. C., Aznar, J., Martin, E. \& Iglesias, M. C. (1980). Synergy between cefotaxime, cefsulodin, azlocillin, mezlocillin and aminoglycosides against carbenicillin resistant or sensitive Pseudomonas aeruginosa. Journal of Antimicrobial Chemotherapy 6, $471-7$.

Perfect, J. R. \& Durack, D. T. (1981). Pharmacokinetics of cefoperazone, moxalactam, cefotaxime, trimethoprim and sulfamethoxazole in experimental meningitis. Journal of Antimicrobial Chemotherapy 8, 49-58.

Reyes, M. P., Palutke, W. A., Wylin, R. F. \& Lerner, A. M. (1973). Pseudomonas endocarditis in the Detroit Medical Center 1969-1972. Medicine 52, 173-94.

Sande, M. A. \& Irvin, R. G. (1974). Penicillin-aminoglycoside synergy in experimental Streptococcus viridans endocarditis. Journal of Infectious Diseases 129, 572-6.

Schaad, U. B., McCracken, G. H. Jr., Loock, C. A. \& Thomas, M. L. (1981). Pharmacokinetics and bacteriologic efficacy of moxalactam, cefotaxime, cefoperazone and rocephin in experimental bacterial meningitis. Journal of Infectious Diseases 143, 156-63.

Scheld, W. M., Fink, F. N., Fletcher, D. D. \& Sande, M. A. (1979a). Mecillinam-ampicillin synergism in experimental Enterobacteriaceae meningitis. Antimicrobial Agents and Chemotherapy 16, 271-9.

Scheld, W. M., Fletcher, D. D., Fink, F. N. \& Sande, M. A. (1979b). Response to therapy in experimental rabbit model of meningitis due to Listeria monocytogenes. Journal of Infectious Diseases 140, 287-94.

Scheld, W. M., Kelly, W. J. IV, \& Sande, M. A. (1980). Comparison of mezlocillin, azlocillin, piperacillin, and cefsulodin with tobramycin, ticarcillin, and carbenicillin, alone or in combination, in the therapy of experimental Pseudomonas meningitis. Current Chemotherapy and Infectious Diseases: Proceedings of the Jith International Congress of Chemotherapy 2, 1036-8.

Scheld, W. M. (1981). Pathophysiological correlates in bacterial meningitis. Journal of Infection 3, Suppl., 5-19.

Scheld, W. M., Calderone, R. A., Alliegro, G. M. \& Sande, M. A. (1981). Yeast adherence in the pathogenesis of candida endocarditis. Proceedings of the Society for Experimental Biology and Medicine 168, 208-13.

Scheld, W. M. \& Sande, M. A. (1982). Evaluation of combination antibiotic therapy in experimental animal models of infection. Combination Antibiotic Therapy in the Compromised Host (Klastersky, J. \& Staquet, M. J., Eds), pp. 17-41, Raven Press, New York.

Scheld, W. M., Brodeur, J. P. \& Keeley, J. M. (1982). Evaluation of mezlocillin in discriminative animal models of infection. Journal of Antimicrobial Chemotherapy 9, Suppl. A, 51-64.

Slàck, M. P. E. (1981). Anti-pseudomonal $\beta$-lactams. Journal of Antimicrobial Chemotherapy 8, $165-70$.

Slaughter, L., Morris, J. E. \& Starr, A. (1973). Prosthetic valvular endocarditis. A 12-year review. Circulation 47, 1319-26. 
Steers, E., Foltz, E. L. \& Graves, B. S. (1959). An inocula replicating apparatus for routine testing of bacterial susceptibility to antibiotics. Antimicrobial Chemotherapy 9, 307-11.

Strausbaugh, L. J. \& Sande, M. A. (1978). Factors influencing the therapy of experimental Proteus mirabilis meningitis in rabbits. Journal of Infectious Diseases 137, 251-60.

Tselentis, J., Cordossis, T. L., Kosmidis, J., Lambropoulous, S. \& Melissinos, K. (1981). Comparative activity and $\beta$-lactamase stability of carbenicillin, ticarcillin, azlocillin, mezlocillin and cefotaxime. Journal of Antimicrobial Chemotherapy 8, 317-21.

Weinstein, W. M., Onderdonk, A. B., Bartlett, J. G. \& Gorbach, S. L. (1974). Experimental intra-abdominal abscesses in rats: development of an experimental model. Infection and Immunity 10, 1250-5.

Weinstein, W. M., Onderdonk, A. B., Bartlett, J. G., Louie, T. J. \& Gorbach, S. L, (1975). Antimicrobial therapy of experimental intraabdominal sepsis. Journal of Infectious Diseases 132, 282-6.

Wenzel, R. P., Osterman, C. A., Townsend, T. R., Veazey, J. M. Jr., Servis, K. H., Miller, L. S., Craven, R. B., Miller, G. B. Jr. \& Jackson, R. S. (1979). Development of a statewide program for surveillance and reporting of hospital-acquired infections. Journal of Infectious Diseases 140, 741-6.

White, A. R., Comber, K. R. \& Sutherland, R. (1980). Comparative bactericidal effects of azlocillin and ticarcillin against Pseudomonas aeruginosa. Antimicrobial Agents and Chemotherapy 18, 182-9.

White, G. W., Malow, J. B., Zimelis, V. M., Pahlavanzadeh, H., Panwalker, A. P. \& Jackson, G. G. (1979). Comparative in vitro activity of azlocillin, ampicillin, mezlocillin, piperacillin, and ticarcillin, alone and in combination with an aminoglycoside. Antimicrobial Agents and Chemotherapy 15, 540-3.

Winston, D. J., Sidell, J., Hairston, J. \& Young, L. S. (1979). Antimicrobial therapy of septicemia due to Klebsiella pneumoniae in neutropenic rats. Journal of Infectious Diseases 139, 377-88.

Wise, B. L., Mathis, J. L. \& Jawetz, E. (1969). Infections of the central nervous system due to Pseudomonas aeruginosa. Journal of Neurosurgery 31, 432-4.

Wise, R., Andrews, J. M. \& Bedford, K. A. (1978a). Comparison of the in vitro activity of Bay K 4999 and piperacillin, two new anti-Pseudomonal broad-spectrum penicillins, with other $\beta$-lactam drugs. Antimicrobial Agents and Chemotherapy 14, 549-52.

Wise, R., Gillett, A. P., Andrews, J. M. \& Bedford, K. A. (1978b). Activity of azlocillin and mezlocillin against Gram-negative organisms: Comparison with other penicillins. Antimicrobial Agents and Chemotherapy 13, 559-65.

Zak, O. (1980). Scope and limitations of experimental chemotherapy. Experientia 36, 479-83. 